\title{
Faktor-Faktor yang Mempengaruhi Konversi Lahan Pertanian di Subak Sebuah, Kelurahan Kerobokan, Kecamatan Kuta Utara, Kabupaten Badung, Bali
}

\author{
NI LUH RISKA WIRYANTINI, I WAYAN WIDYANTARA, \\ IDA AYU LISTIA DEWI \\ Program Studi Agribisnis, Fakultas Pertanian, Universitas Udayana \\ J1. PB Sudirman Denpasar 80232 \\ Email: riskawiryantini23@gmail.com \\ widyantara@unud.ac.id
}

\begin{abstract}
Factors Affecting Agricultural Land Conversion in the Irrigation Organization of Subak Sebuah, Kerobokan Urban Village, Sub-District of Kuta Utara, Badung Regency, Bali
\end{abstract}

The research aimed to investigate the factors that affect the conversion of agricultural land and the dominant factors that affect the conversion of agricultural land in the traditional irrigation organization of Subak Sebuah, located at Kerobokan Urban Village, Sub-District of Kuta Utara, Badung Regency, Bali. The location was chosen purposively in Subak Sebuah, Kerobokan Urban Village, Sub-District of Kuta Utara, Badung Regency, Bali. The number of respondents was 70 people by using quota sampling method. This research used factor analysis. The findings showed that factors affecting the conversion of agricultural land in the Subak Sebuah are economic factors (land selling price, land leasing price, farm income, household expenditure), social factors (following neighbors, age, and the number of family members working outside the agricultural sector) and land conditions factors (availability of irrigation water, access to irrigation water, land area before conversion, and location of land). The dominant factors affecting the conversion of agricultural land in Subak Sebuah, Kerobokan Urban Village, Sub-District of Kuta Utara, Badung Regency, Bali are the economic factors.

Keywords: conversion of agricultural land, subak, dominant factors.

\section{Pendahuluan}

\subsection{Latar Belakang}

Kabupaten Badung merupakan salah satu penyumbang PDRB di Bali yang mengandalkan industri pariwisata sebagai sektor unggulan (leading sector) bagi perekonomian di Bali. Pariwisata menjadi salah satu sektor yang diandalkan dalam pembangunan, menjadikan sektor pariwisata sebagai sumber pendapatan utama bagi Kabupaten Badung. Pariwisata sebagai sektor unggulan yang dikembangkan di Kabupaten Badung, ditunjang oleh sektor pertanian karena keanekaragaman sumber 
pangan yang ada di Kabupaten Badung dapat juga memberikan daya tarik tersendiri bagi para wisatawan (BPS Kabupaten Badung, 2014a).

Industri kepariwisataan tersebut didukung oleh penyediaan akomodasi dan makan serta minum untuk mencukupi kebutuhan wisatawan. Penyediaan akomodasi dan makan serta minum memiliki persentase PDRB menurut lapangan usaha dari tahun 2012 s.d. 2016 yang tertinggi di Kabupaten Badung dengan rata-rata 27,96\% (BPS Kabupaten Badung, 2017a). Kecamatan kedua di Kabupaten Badung yang di wilayahnya terdapat usaha akomodasi terbanyak setelah Kuta adalah Kecamatan Kuta Utara. Total usaha akomodasi yang tercatat di wilayah ini sebanyak 899 unit dengan tiga besar jenis usaha adalah pondok wisata, penginapan khusus, dan villa. Bila dibandingkan dengan total jumlah usaha akomodasi, persentase usaha di kecamatan ini sebesar 26,19\% (Surata dkk, 2015).

Kecamatan Kuta Utara menunjukkan pertumbuhan penduduk yang selalu mengalami peningkatan setiap tahunnya dari tahun 2012 s.d. 2020 (BPS Kabupaten Badung, 2014b). Pertumbuhan penduduk secara otomatis menyebabkan peningkatan kebutuhan pangan, namun juga menyebabkan peningkatan kebutuhan tempat tinggal dan lapangan usaha. Seiring dengan perkembangan waktu, ekspansi pembangunan infrastruktur pariwisata (hotel, villa, bungalow, restoran, pertokoan, dan sebagainya) yang demikian cepat, serta pertumbuhan penduduk yang semakin meningkat mengakibatkan penyempitan luas lahan pertanian secara drastis.

Konversi lahan pertanian dalam lima tahun berturut-turut dari tahun 2012 s.d. 2016, Kecamatan Kuta Utara mengalami konversi lahan tertinggi diantara enam kecamatan lainnya di Kabupaten Badung dengan rata-rata 44,8 Ha/tahun (BPS Kabupaten Badung, 2017b). Kecamatan Kuta Utara memiliki 19 Subak yang terdiri dari Subak Sebuah, Subak Kedampang, Subak Petitenget, Subak Basangkasa, Subak Tegal, Subak Muding, Subak Canggu, Subak Liplip, Subak Umadesa, Subak Umaalas, Subak Semat, Subak Perancak, Subak Banjarsari, Subak Dawas, Subak Daksina, Subak Bantan, Subak Bernasi, Subak Saih, dan Subak Gaji. Hampir setiap Subak di Kecamatan Kuta Utara mengalami konversi lahan.

Subak yang paling banyak mengalami konversi lahan pertanian di Kecamatan Kuta Utara dari kurun waktu 2011 s.d. 2015 adalah Subak Sebuah yaitu mencapai 43,00 Ha (BPP Kuta Utara, 2016). Pesatnya perkembangan konversi lahan pertanian ini terjadi tentu disebabkan oleh beberapa faktor yang mempengaruhi konversi lahan pertanian dan jika konversi lahan ini terus terjadi maka akan menyebabkan lahan pertanian di Subak Sebuah semakin sempit. Pemerintah harus tetap mengetahui faktor-faktor yang mendorong terjadinya konversi lahan pertanian. Penelitian ini dibutuhkan untuk meninjau kembali upaya pencegahan dan pengendalian konversi lahan pertanian perlu dilakukan untuk meminimalisir konversi lahan pertanian pada tahun mendatang.

\subsection{Tujuan Penelitian}

Penelitian ini bertujuan untuk mengetahui: (1) faktor-faktor yang mempengaruhi konversi lahan pertanian di Subak Sebuah, Kelurahan Kerobokan, Kecamatan Kuta 
Utara, Kabupaten Badung, Bali dan (2) faktor dominan yang mempengaruhi konversi lahan pertanian di Subak Sebuah, Kelurahan Kerobokan, Kecamatan Kuta Utara, Kabupaten Badung, Bali.

\section{Metode Penelitian}

\subsection{Lokasi dan waktu penelitian}

Penelitian ini dilaksanakan di Subak Sebuah, Kelurahan Kerobokan, Kecamatan Kuta Utara, Kabupaten Badung, Bali. Penelitian dilaksanakan mulai dari bulan Maret s.d. Mei 2017. Pemilihan lokasi penelitian dilakukan secara sengaja (purposive) dengan pertimbangan Subak Sebuah merupakan subak yang paling banyak mengalami konversi lahan pertanian di Kecamatan Kuta Utara dari kurun waktu 2011 sampai 2015 yaitu mencapai 43,00 Ha.

\subsection{Populasi dan Sampel}

Populasi pada penelitian ini adalah pemilik lahan sawah yang masih atau pernah menjadi anggota di Subak Sebuah, Kelurahan Kerobokan, Kecamatan Kuta Utara, Kabupaten Badung, Bali yang mengkonversikan lahannya ke sektor non pertanian. Jumlah populasinya tidak diketahui (unlimited population), sehingga teknik sampling yang digunakan yaitu nonprobability sampling. Sampel adalah sebanyak 70 orang responden dengan syarat petani pernah atau masih menjadi anggota Subak Sebuah, yang menjual atau menyewakan sebagian maupun seluruh lahan sawahnya. Penentuan sampel dalam penelitian ini menggunakan metode sampling kuota.

\subsection{Sumber, Jenis dan Metode Pengumpulan Data}

\subsubsection{Sumber dan jenis data}

Sumber data penelitian ini berasal dari data primer dan data sekunder. Data primer mengenai faktor-faktor yang mempengaruhi konversi lahan pertanian diperoleh dari responden dengan cara wawancara menggunakan kuisioner maupun wawancara secara mendalam. Data sekunder berupa data yang didapat dari Balai Penyuluhan Pertanian Tanaman Pangan Kecamatan Kuta Utara dan Badan Pusat Statistik, hasil penelitian sebelumnya yang terkait dengan penelitian ini, buku-buku serta data-data melalui internet.

Jenis data penelitian ini adalah kualitatif dan kuantitatif. Data kuantitatif antara lain, luas konversi lahan pertanian, penerimaan usahatani, pengeluaran rumah tangga, umur, jumlah anggota keluarga yang bekerja di luar sektor pertanian, luas lahan sebelum konversi lahan, dan jarak lahan dengan jalan utama. Data kualitatif berupa struktur organisasi subak, pendapat atau alasan yang dikemukakan pemilik lahan dalam mengkonversi lahannnya yang terdiri dari persepsi mengenai harga jual lahan, harga sewa tanah, mengikuti tetangga, ketersediaan air irigasi, dan akses air irigasi, identitas responden, profil Subak Sebuah, dan profil Kelurahan Kerobokan. 


\subsubsection{Metode Pengumpulan Data}

Metode yang digunakan dalam penelitian ini dikumpulkan dengan menggunakan teknik: (1) observasi yaitu mengadakan pengamatan langsung ke lokasi penelitian, (2) wawancara terstruktur berupa tanya jawab langsung dengan narasumber terkait dan responden penelitian, dengan menggunakan daftar pertanyaan dan kuisioner yang telah dipersiapkan terlebih dahulu, dan (3) studi pustaka yaitu penelitian yang dilakukan dengan membaca literatur-literatur dan referensi-referensi yang didapat dari berbagai buku-buku pustaka, dokumen tertulis maupun elektronik dari lembaga atau institusi yang berhubungan dalam penelitian ini.

\subsection{Variabel Penelitian dan Pengukuran}

Variabel dan pengukuran dalam penelitian ini adalah faktor-faktor yang mempengaruhi konversi lahan pertanian di Subak Sebuah, Kelurahan Kerobokan, Kecamatan Kuta Utara, Kabupaten Badung, Bali, yaitu faktor ekonomi, faktor sosial, dan faktor kondisi lahan. Faktor ekonomi terdiri dari harga jual lahan, harga sewa tanah, penerimaan usahatani, dan pengeluaran rumah tangga. Faktor sosial terdiri dari mengikuti tetangga, umur, dan jumlah anggota keluarga yang bekerja di luar sektor pertanian. Faktor kondisi lahan terdiri dari ketersediaan air irigasi, akses air irigasi, luas lahan sebelum konversi, dan letak lahan.

\subsection{Metode Analisis Data}

\subsubsection{Uji instrumen pengumpulan data}

A. Uji validitas

Validitas menurut Suharsimi (2002) adalah suatu ukuran untuk menunjukkan tingkat-tingkat kevalidan atau kesahihan suatu instrument. Uji validitas dilakukan dengan membandingkan nilai $r$ hitung dengan nilai $r$ tabel. Pernyataan dikatakan valid apabila nilai $\mathrm{r}$ hitung $>$ nilai $\mathrm{r}$ tabel dengan menggunakan level signifikan 5\%. Batas minimum dianggap memenuhi syarat validitas apabila $r=0,235$.

B. Uji reliabilitas

Reliabilitas adalah derajat ketepatan, ketelitian atau keakuratan yang ditunjukkan oleh instrumen pengukuran. Variabel dikatakan reliabel jika nilai Cronbach Alpha lebih dari 0,6 (Ghozali,2006).

\subsubsection{Analisis faktor}

Tujuan penelitian pertama dianalisis deskriptif dengan pendekatan analisis faktor. Analisis faktor digunakan untuk mengidentifikasi dimensi suatu struktur dan kemudian menentukan sampai sebarapa jauh setiap variabel dapat dijelaskan oleh setiap dimensi (Ghozali, 2006). 
Tahapan menggunakan analisis faktor dalam penelitian ini sebagai berikut.

1) Membuat matrik korelasi

Sebelum masuk proses analisis faktor, terdapat asumsi dasar yaitu asumsi ukuran kecukupan sampling yang diuji dengan Kaiser-Meyer Olkin (KMO) dan Measure of Sampling Adequency (MSA). Angka KMO dan MSA diisyaratkan minimal 0,5. Kriteria dengan melihat probabilitas (signifikan), angka Sig. >0,05 maka $\mathrm{H}_{0}$ diterima dan angka Sig. $<0,05$ maka $\mathrm{H}_{0}$ ditolak (Santoso,2010).

2) Menentukan jumlah faktor

Faktor yang dipilih adalah faktor yang mempunyai eigenvalue lebih besar atau sama dengan satu. Penentuan faktor dapat juga didasarkan pada percentage of variance suatu faktor dapat menjadi pertimbangan konsumen apabila memilih nilai lebih besar dari 5\% dan apabila didasarkan pada cumulative of variance ketentuannya adalah nilai minimum sebesar 60\%, maka faktor tersebut dapat digunakan dalam model.

3) Interpretasi faktor

Langkah-langkah interpretasi matriks faktor, yaitu: (1) memeriksa faktor loading terbesar untuk setiap variabel, (2) mengidentifikasi faktor loading terbesar untuk setiap variabel, (3) menggabungkan variabel ke dalam faktor, (4) menghapus variabel apabila faktor loading variabel signifikansi pada beberapa faktor dan nilai komunalitas variabel lebih kecil dari 0,5, dan (5) memberikan nama atau label pada faktor terbentuk yang mencerminkan arti gabungan dari variabel-variabel penyusunnya.

Tujuan penelitian kedua dianalisis deskriptif dengan menggunakan nilai percentage of variance eigenvalues tertinggi. Penentuan faktor yang berpengaruh dominan digunakan nilai percentage of variance eigenvalues tertinggi. Nilai percentage of variance yang tertinggi dianggap sebagai faktor dominan yang mewakili faktor.

\section{Hasil Penelitian}

\subsection{Karakteristik Umum Responden}

Sebagian besar responden di Subak Sebuah berumur produktif sebesar 84,3\%. Menurut BPS (2012) umur produktif berkisar antara 15 s.d. 64 tahun. Pendidikan terakhir responden terbanyak adalah SD sederajat (40,0\%). Tahun 2016 terjadi penurunan petani sebagai pekerjaan pokok $(27,5 \%)$ dan peningkatan wiraswasta $(50,0 \%)$ dan pegawai swasta sebagai pekerjaan pokok $(50,0 \%)$ dari tahun sebelumnya. Jumlah anggota keluarga petani responden di Subak Sebuah dominan lima orang $(27,1 \%)$. Lahan yang paling banyak mengalami konversi seluas 12 s.d. 20 are (30,0\%). Luas lahan yang mengalami konversi lahan terbanyak terjadi pada tahun 2014 s.d. 2017 yaitu sebesar 613 are $(38,2 \%)$ dengan jumlah responden sebanyak 28 orang responden $(40,0 \%)$. 


\subsection{Faktor-Faktor yang Mempengaruhi Konversi Lahan Pertanian}

Faktor-faktor yang mempengaruhi konversi lahan pertanian di Subak Sebuah, Kelurahan Kerobokan, Kecamatan Kuta Utara, Kabupaten Badung dalam penelitian ini adalah faktor ekonomi, faktor sosial, dan faktor kondisi lahan. Faktor ekonomi terdiri dari empat indikator antara lain harga jual lahan, harga sewa tanah, penerimaan usahatani, dan pengeluaran rumah tangga. Faktor sosial terdiri dari tiga indikator antara lain mengikuti tetangga, umur, dan jumlah anggota keluarga yang bekerja di luar sektor pertanian. Faktor kondisi lahan terdiri dari empat indikator antara lain ketersediaan air irigasi, akses air irigasi, luas lahan sebelum konversi, dan letak lahan.

\subsubsection{Identifikasi indikator pembentuk faktor dalam analisis faktor}

Penelitian ini menggunakan pendekatan confirmatory factor analysis. Faktor yang terbentuk telah ditetapkan terlebih dahulu.

1) Uji Kaiser Meyer Olkin (KMO)

Tabel 1.

Hasil Pengujian KMO

\begin{tabular}{clc}
\hline No & \multicolumn{1}{c}{ Faktor } & Nilai Kaiser Meyer Olkin (KMO) \\
\hline 1 & Faktor Ekonomi & 0,836 \\
2 & Faktor Sosial & 0,689 \\
3 & Faktor Kondisi Lahan & 0,767 \\
\hline
\end{tabular}

Sumber : Analisis data primer, 2017

Hasil uji Tabel 1 memperlihatkan faktor ekonomi, sosial dan kondisi lahan memiliki nilai $\mathrm{KMO} \geq 0,5$, maka masing-masing faktor memiliki kecukupan sampel untuk analisis faktor.

2) Measures of Sampling Adequacy (MSA)

Tabel 2.

Angka Korelasi Anti Image Matrices

\begin{tabular}{cclc}
\hline No & Faktor & \multicolumn{1}{c}{ Indikator } & $\begin{array}{c}\text { Anti Image } \\
\text { Correlation }\end{array}$ \\
\hline 1 & & Harga jual lahan $\left(\mathrm{X}_{1.1}\right)$, & 0,867 \\
2 & Faktor ekonomi & Harga sewa tanah $\left(\mathrm{X}_{1.2}\right)$, & 0,849 \\
3 & $\left(\mathrm{X}_{1}\right)$ & Penerimaan usahatani $\left(\mathrm{X}_{1.3}\right)$, & 0,818 \\
4 & & Pengeluaran rumah tangga $\left(\mathrm{X}_{1.4}\right)$, & 0,820 \\
\hline 5 & \multirow{2}{*}{ Faktor sosial } & Mengikuti tetangga $\left(\mathrm{X}_{2.1}\right)$, & 0,648 \\
6 & $\left(\mathrm{X}_{2}\right)$ & Umur $\left(\mathrm{X}_{2.2}\right)$, & 0,649 \\
7 & & Jumlah anggota keluarga $\left(\mathrm{X}_{2.3}\right)$, & 0,839 \\
\hline 8 & \multirow{2}{*}{ Faktor kondisi } & Ketersediaan air irigasi $\left(\mathrm{X}_{3.1}\right)$, & 0,760 \\
9 & lahan & Akses air irigasi $\left(\mathrm{X}_{3.2}\right)$, & 0,775 \\
10 & $\left(\mathrm{X}_{3}\right)$ & Luas lahan sebelum konversi $\left(\mathrm{X}_{3.3}\right)$, & 0,758 \\
11 & & Letak lahan $\left(\mathrm{X}_{3.4}\right)$, & 0,776 \\
\hline
\end{tabular}

Sumber: Analisis data primer, 2017 
Tabel 2 menunjukkan nilai anti image correlation seluruh indikator variabel penelitian ini. Semua angka korelasi indikator variabel mulai dari indikator harga jual lahan pada faktor ekonomi $\left(\mathrm{X}_{1.1}\right)$ hingga indikator letak lahan pada faktor kondisi lahan $\left(\mathrm{X}_{3.4}\right)$ mempunyai nilai yang lebih besar dari 0,5 maka dapat dikatakan bahwa seluruh variabel penelitian ini dapat digunakan dalam analisis selanjutnya.

3) Factoring

Tabel 3.

Total Variance Explained

\begin{tabular}{ccccccccc}
\hline & \multicolumn{2}{c}{$\begin{array}{c}\text { Initial Eigenvalues } \\
\text { Faktor Ekonomi }\end{array}$} & \multicolumn{3}{c}{$\begin{array}{c}\text { Initial Eigenvalues } \\
\text { Faktor Sosial }\end{array}$} & \multicolumn{3}{c}{$\begin{array}{c}\text { Initial Eigenvalues } \\
\text { Faktor Kondisi Lahan }\end{array}$} \\
\hline \multirow{2}{*}{ Total } & $\begin{array}{c}\text { \% of } \\
\text { Variance }\end{array}$ & $\begin{array}{c}\text { Cumulative } \\
\%\end{array}$ & Total & $\begin{array}{c}\text { \% of } \\
\text { Variance }\end{array}$ & $\begin{array}{c}\text { Cumulative } \\
\%\end{array}$ & Total & \multicolumn{1}{c}{$\begin{array}{c}\% \text { of } \\
\text { Variance }\end{array}$} & $\begin{array}{c}\text { Cumulative } \\
\%\end{array}$ \\
\hline 3,137 & 78,414 & 78,414 & 2,278 & 75,941 & 75,941 & 2,602 & 65,062 & 65,062 \\
0,406 & 10,140 & 88,553 & 0,492 & 16,411 & 92,353 & 0,607 & 15,181 & 80,243 \\
0,240 & 6,006 & 94,560 & 0,229 & 7,647 & 100,000 & 0,444 & 11,104 & 91,347 \\
0,218 & 5,440 & 100,000 & & & & 0,346 & 8,653 & 100,000 \\
\hline
\end{tabular}

Sumber : Analisis data primer, 2017

Tabel 3, terlihat bahwa ada dua faktor yang terbentuk untuk faktor ekonomi, sosial dan kondisi lahan, hal ini bisa dilihat dari angka eigenvalue pada faktor ekonomi yaitu variabel satu yang lebih besar dari satu, faktor sosial yaitu variabel satu yang lebih besar dari satu. faktor kondisi lahan yaitu variabel satu yang lebih besar dari satu. Sedangkan variabel seterusnya memiliki nilai eigenvalue lebih kecil dari satu, sehingga tidak diperhitungkan dalam proses ini.

Tabel 4.

Component Matrix ${ }^{a}$

\begin{tabular}{|c|c|}
\hline \multirow{2}{*}{ Faktor Ekonomi } & Component \\
\hline & 1 \\
\hline Harga jual lahan $\left(\mathrm{X}_{1.1}\right)$ & 0,848 \\
\hline Harga sewa tanah $\left(\mathrm{X}_{1.2}\right)$, & 0,870 \\
\hline Penerimaan usahatani $\left(\mathrm{X}_{1.3}\right)$, & 0,913 \\
\hline Pengeluaran rumah tangga $\left(\mathrm{X}_{1.4}\right)$, & 0,910 \\
\hline \multirow[b]{2}{*}{ Faktor Sosial } & Component \\
\hline & 1 \\
\hline Mengikuti tetangga $\left(\mathrm{X}_{2.1}\right)$, & 0,903 \\
\hline $\operatorname{Umur}\left(\mathrm{X}_{2.2}\right)$ & 0,903 \\
\hline Jumlah anggota keluarga yang bekerja di luar sektor pertanian $\left(X_{2.3}\right)$, & 0,805 \\
\hline \multirow{2}{*}{ Faktor Kondisi Lahan } & Component \\
\hline & 1 \\
\hline Ketersediaan air irigasi $\left(\mathrm{X}_{3.1}\right)$, & 0,820 \\
\hline Akses air irigasi $\left(\mathrm{X}_{3.2}\right)$ & 0,797 \\
\hline Luas lahan sebelum konversi $\left(\mathrm{X}_{3.3}\right)$, & 0,818 \\
\hline Letak lahan $\left(\mathrm{X}_{3.4}\right)$ & 0,791 \\
\hline
\end{tabular}

Sumber : Analisis data primer, 2017

Tabel 4 menunjukkan distribusi ke 11 indikator ke masing-masing faktor yang terbentuk. Angka-angka yang terdapat dalam komponen matrik adalah faktor loading 
yang menunjukkan besarnya korelasi antara satu indikator variabel dengan faktor yang terbentuk. Ketiga faktor tersebut menghasilkan matrik faktor loading $\geq 0,5$ yang merupakan koefisien korelasi antar variabel dengan faktor-faktor tersebut.

\subsubsection{Variabel-variabel yang mewakili setiap faktor yang mempengaruhi konversi lahan pertanian}

Faktor-faktor yang mempengaruhi konversi lahan pertanian di Subak Sebuah, Kelurahan Kerobokan, Kecamatan Kuta Utara, Kabupaten Badung, Bali dapat dilihat pada Gambar 1 berikut.

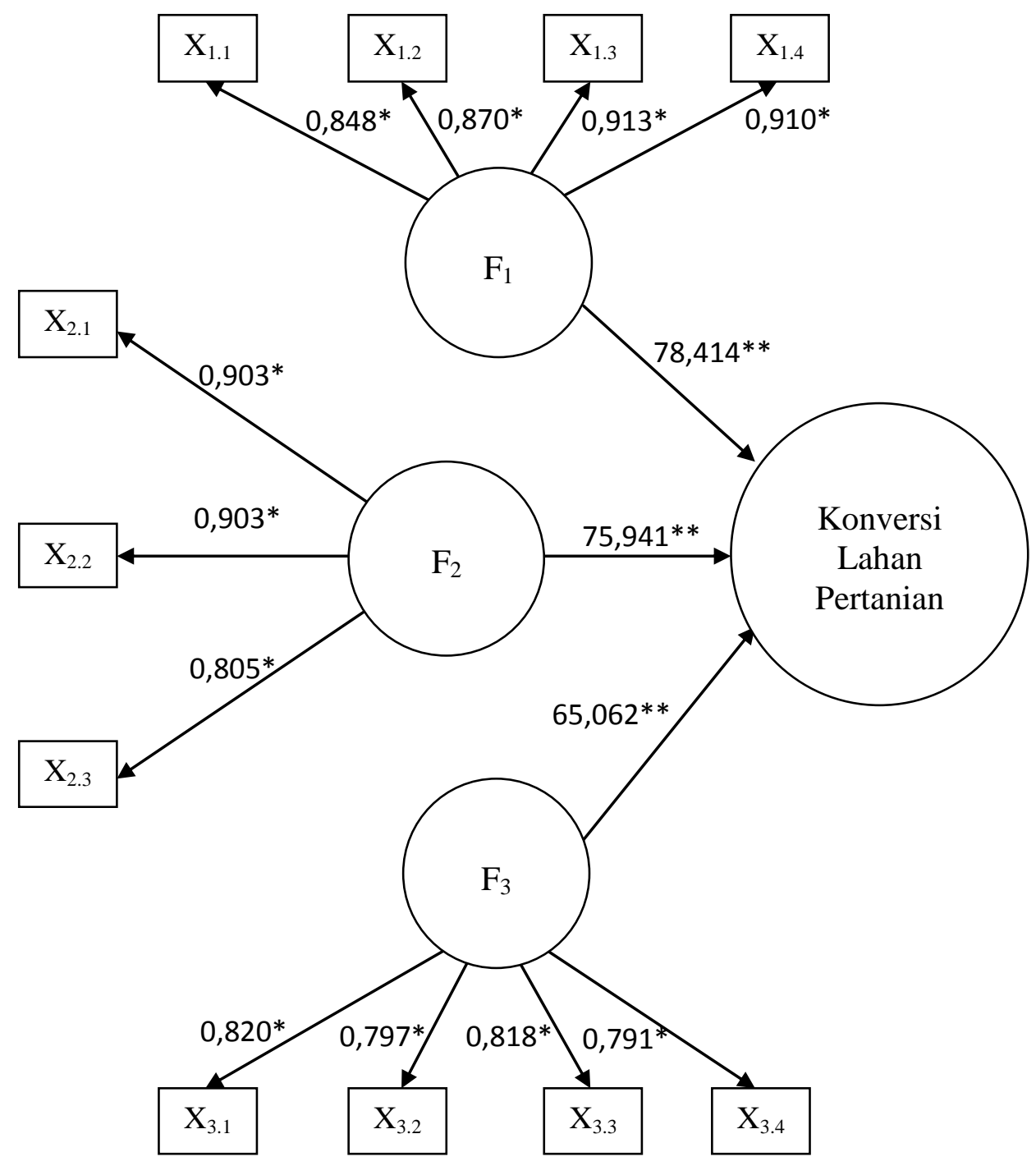

Gambar 1.

Keterangan:

Model Faktor yang Dianalisis

(*) : Faktor loading

(**) : Percentage of variance 
Faktor-faktor yang mempengaruhi konversi lahan pertanian di Subak Sebuah, Kelurahan Kerobokan, Kecamatan Kuta Utara, Kabupaten Badung adalah faktor ekonomi, sosial dan kondisi lahan yang dapat dijabarkan sebagai berikut. (1) faktor pertama adalah faktor ekonomi, dengan percentage of variance $78,414 \%$. Faktor ini terdiri dari indikator variabel harga jual lahan, harga sewa tanah, penerimaan usahatani, dan pengeluaran rumah tangga, (2) faktor kedua adalah faktor sosial, dengan percentage of variance $75,941 \%$. Faktor ini terdiri dari indikator variabel mengikuti tetangga, umur, dan jumlah anggota keluarga yang bekerja di luar sektor pertanian, dan (3) faktor ketiga adalah faktor kondisi lahan, dengan percentage of variance $65,062 \%$. Faktor ini terdiri dari indikator variabel ketersediaan air irigasi, akses air irigasi, luas lahan sebelum konversi, dan letak lahan.

\subsection{Faktor Dominan Penentu Konversi Lahan Pertanian}

Faktor yang berpengaruh dominan ditentukan dari nilai percentage of variance eigenvalues tertinggi dari ketiga faktor yang ada. Faktor dominan yang mempengaruhi konversi lahan pertanian di Subak Sebuah, Kelurahan Kerobokan, Kecamatan Kuta Utara Kabupaten Badung adalah faktor ekonomi (percentage of variance sebesar $78,414 \%)$.

\section{Simpulan dan Saran \\ 4.2 Simpulan}

Hasil penelitian disimpulkan bahwa (1) faktor-faktor yang mempengaruhi konversi lahan pertanian di Subak Sebuah, Kelurahan Kerobokan, Kecamatan Kuta Utara, Kabupaten Badung, Bali adalah faktor ekonomi (harga jual lahan, harga sewa tanah, penerimaan usahatani, dan pengeluaran rumah tangga), faktor sosial (mengikuti tetangga, umur, dan jumlah anggota keluarga yang bekerja di luar sektor pertanian) dan faktor kondisi lahan (ketersediaan air irigasi, akses air irigasi, luas lahan sebelum konversi, dan letak lahan) dan (2) faktor dominan yang mempengaruhi konversi lahan pertanian di Subak Sebuah, Kelurahan Kerobokan, Kecamatan Kuta Utara Kabupaten Badung, Bali adalah faktor ekonomi.

\subsection{Saran}

Berdasarkan hasil penelitian dan kesimpulan yang ada maka dapat dikemukakan saran sebagai berikut. (1) perlunya pemberian insentif dari pemerintah kepada petani dalam bentuk pembebasan pajak lahan, serta bantuan subsidi saprodi sehingga petani termotivasi untuk tetap mengusahakan lahannya dan (2) sebaiknya pemerintah membatasi perizinan pembangunan infrastruktur non pertanian.

\section{$5 \quad$ Ucapan Terima Kasih}

Terimakasih kepada Pekaseh Subak Sebuah Kelurahan Kerobokan I Nengah Nirda, Pangliman, serta seluruh petani yang telah membantu dalam proses pelaksanaan penelitian. 


\section{Daftar Pustaka}

Badan Pusat Statistik. 2012. Proyeksi Penduduk Menurut Provinsi Tahun 2010-2035. Diunduh pada: http://bps.go.id/ (tanggal 14 Agustus 2017).

Badan Pusat Statistik Kabupaten Badung. 2014a. Kabupaten Badung Dalam Angka 2014. Katalog BPS: 1102001.5103. Diunduh pada: https://badungkab.bps.go.id/ (tanggal 7 Desember 2016).

Badan Pusat Statistik Kabupaten Badung. 2014b. Kepadatan Penduduk Menurut Kecamatan, 2010-2020 (Jiwa/Km ${ }^{2}$ ). Diunduh pada: https://badungkab.bps.go.id/ (tanggal 22 Maret 2017).

Badan Pusat Statistik Kabupaten Badung. 2017a. Produk Domestik Regional Bruto Kabupaten Badung Menurut Lapangan Usaha 2012-2016. Katalog BPS: 9302008.5103. Diunduh pada: https://badungkab.bps.go.id/ (tanggal 04 Oktober 2017).

Badan Pusat Statistik Kabupaten Badung. 2017b. Kabupaten Badung Dalam Angka 2017. Katalog BPS: 1102001.5103. Diunduh pada: https://badungkab.bps.go.id/ (tanggal 30 Agustus 2017).

Balai Penyuluhan Pertanian Tanaman Pangan Kecamatan Kuta Utara. 2016. Luas Subak dan Konversi (Alih Fungsi) Lahan Pertanian di Kecamatan Kuta Utara, Kabupaten Badung, Bali. Badung: Balai Penyuluhan Pertanian Tanaman Pangan Kecamatan Kuta Utara.

Ghozali, Imam. 2006. Aplikasi Analis Multivariate dengan Program SPSS. Cetakan keempat. Semarang: Badan Penerbit Universitas Diponegoro.

Santoso, S. 2010. Statistik Multivariat Konsep dan Aplikasi dengan SPSS. Jakarta: PT Elex Media Komputindo.

Suharsimi, A. 2002. Prosedur Penelitian: Suatu Pendekatan Praktik. Jakarta: Asdi Mahasatya.

Surata, I Ketut, Ni Made Eka Mahadewi, I Wayan Mertha, I Putu Eka N. Kencana, Made Sulasa Jaya, Ismoyo S. Sumarlan, Putu Esa Widahartana, Putu Irma Yunita, dan I Putu Anom. 2015. Studi Pemetaan Penawaran dan Permintaan Kebutuhan Usaha Akomodasi di Kabupaten Badung. Kerjasama Badan Promosi Pariwisata Daerah Pemerintah Kabupaten Badung dengan Sekolah Tinggi Pariwisata Nusa Dua Bali. 